\title{
Identification of native Dendrobium species in Thailand by PCR-RFLP of rDNA-ITS and chloroplast DNA
}

\author{
Surin Peyachoknagul ${ }^{\mathrm{a}, \mathrm{b}, *}$, Chareerat Mongkolsiriwatana ${ }^{\mathrm{b}, \mathrm{c}}$, Sirinrat Wannapinpong $^{\mathrm{d}}$, \\ Pattana Srifah Huehne $^{\mathrm{a}, \mathrm{e}}$, Kornsorn Srikulnath ${ }^{\mathrm{a}, \mathrm{b}}$ \\ a Department of Genetics, Faculty of Science, Kasetsart University, Bangkok 10900 Thailand \\ b Centre for Advanced Studies in Tropical Natural Resources, \\ National Research University-Kasetsart University, (CASTNAR, NRU-KU), Bangkok 10900 Thailand \\ c Department of Genetics, Faculty of Liberal Arts and Science, Kasetsart University, \\ Nakhon Pathom 73140 Thailand \\ d Institute of Food Research and Product Development, Kasetsart University, Bangkok 10900 Thailand \\ e Biotechnology Laboratory, Chulabhorn Research Institute, Bangkok 10210 Thailand \\ *Corresponding author, e-mail: fscisrp@ku.ac.th
}

Received 12 Mar 2013

Accepted 10 Mar 2014

\begin{abstract}
The PCR-restriction fragment length polymorphism (PCR-RFLP) approach was successfully developed to identify 25 native Dendrobium species in Thailand. PCR-RFLP of the rDNA-ITS with six restriction enzymes and three chloroplast (cp) DNA regions with five primer-enzyme combinations produced 24 types of DNA patterns altogether. Twenty-three out of the 25 species determined in this study were found to belong to unique classes and were successfully differentiated. Two species, D. crumenatum and D. formosum, possessing the same DNA pattern, however, were identified after cutting the chloroplast DNA fragment amplified by psbC-trnS primer with $M b o$ I enzyme. An effective procedure for identifying each Dendrobium species was developed. PCR-RFLP of the rDNA-ITS with TaqI, which is the most informative enzyme, was used for the early detection of 16 Dendrobium species. To identify the remaining Dendrobium species, PCRRFLP analysis was performed using one more primer-enzyme combination. Our study provides a rapid, simple, and reliable identification method for these Dendrobium species.
\end{abstract}

KEYWORDS: orchid, DNA markers, species verification, internal transcribed spacer

\section{INTRODUCTION}

Orchidaceae is one of the largest and most diverse families of flowering plants, making up to one-tenth of all flowering plant species in the world ${ }^{1}$. The genus Dendrobium, with 1184 species, is the second largest genus in Orchidaceae ${ }^{2}$. They are found in various geographical zones and enormously diverse in growth habits along tropical and subtropical Asia and Northern Australia. In Thailand, Dendrobium spp. is the largest orchid genus with more than 150 native species classified into 14 sections $^{3}$. It is also one of the most popular orchids for commercial production with the drastic increase of demand for cut flower and pot plants over the years. About 8000 novel Dendrobium hybrids have been bred through interspecific hybridizations for different flower morphological characteristics ${ }^{4}$. In contrast, most native Dendrobium species are critically susceptible to deterioration and fragmentation of natural ecosystem because of mass collection from the wild for trade of both flower and pot plant. Hence native Dendrobium species are now considered endangered species (CITES). However, several native Dendrobium species are morphologically similar, thereby making their labelling through vegetative anatomy very difficult except during flowering period. Identification of Dendrobium species becomes necessary for sustainable use and conservation of the plant genetic resources. The development of a simple and reliable approach to identify these plant species is therefore needed.

The internal transcribed spacer (ITS) sequences of the nuclear ribosomal RNA gene (rDNA) are large segment consisting of $18 \mathrm{~S}$ rDNA, 5.8S rDNA and 26S rDNA clustered together with internal transcribed spacers, ITS1 and ITS2, between genes. Notably, ITS sequences have been extensively used to determine genetic diversity and to classify several plants species because they are highly variable ${ }^{5,6}$. Besides the ITS sequences, organelle DNA, chloroplast DNA 
(cpDNA) and mitochondrial DNA (mtDNA), are the other targets of genetic diversity and classification studies due to their maternal inheritance, smaller-sized molecule compared to genomic DNA, and low level of recombination, which make them easier and more reliable to examine the phylogenetic applications ${ }^{7,8}$. The rDNA-ITS or organelle DNAs has been widely used for the above-mentioned applications not only by sequences analysis but also by comparison of their PCR-amplified fragments. The PCR amplified products of rDNA-ITS or organelle DNA, however, often exhibits a monomorphic band that cannot differentiate among several species within the same genus. Further digestion of their amplicons with restriction enzymes (PCR-restriction fragment length polymorphism; PCR-RFLP) is therefore conducted for displaying the restriction site polymorphisms ${ }^{9}$. PCR-RFLP of the rDNA-ITS ${ }^{10}$ and cpDNA ${ }^{11,12}$ have been extensively used for genetic diversity studies in several plants because of its simplicity, reliability, and practicality.

In Dendrobium, both the sequences of rDNAITS $^{13,14}$ and cpDNA ${ }^{15}$ and the PCR-RFLP of cpDNA $(r b c L \text { gene })^{16}$ were used for species identification and determination of their genetic relationship. Moreover, inter-simple sequence repeat (ISSR) marker was also used for species identification and phylogenetic relationship of 31 Dendrobium spp. in China ${ }^{17}$. These findings collectively suggest that Dendrobium spp. was highly diversified with complex genetic background at the species-level. The molecular identification of native Dendrobium spp. in Thailand however has not yet been reported despite inclusion of several species. In this study, PCR-RFLP of the rDNA-ITS and cpDNA have been conducted for rapid and reliable species identification of 25 native Dendrobium spp. in Thailand. We also developed a specific PCRRFLP procedure to identify these Dendrobium spp., which can be used for trade and conservation.

\section{MATERIALS AND METHODS}

\section{Plant materials and DNA extraction}

Twenty-five Dendrobium species were taken from the in vitro collection of the Biotechnology Laboratory, Chulabhorn Research Institute, Bangkok, Thailand. Each species was morphologically identified following Seidenfaden ${ }^{3}$ before culturing. Total genomic DNA was extracted from the leaves as described previously ${ }^{18}$, and kept at $-80^{\circ} \mathrm{C}$ until used. The quality and concentration of DNA were measured by $1 \%$ agarose gel electrophoresis and spectrophotometric analysis.
Table 1 Names and sequences of the primers used.

\begin{tabular}{ll}
\hline Primer & Sequence $\left(5^{\prime}-3^{\prime}\right)$ \\
\hline Nuclear rDNA & \\
OrRNA1 & ATTGAACCT TATCATT TAGAGG \\
OrRNA2 & GTACT TGTTCGCTATCGGTC \\
Chloroplast DNA & \\
trnS & \\
trnfM & GAGAGAGAGGGATTCGAACC \\
psbC & CATAACCT TGAGGTCACGGG \\
trnS & GGTTCGAATCCCATCTCTCTC \\
trnH & ACGGGAATTGAACCCGCGCA \\
rnK & CCGACTAGTTCCGGGTTCGA \\
\hline
\end{tabular}

${ }^{\mathrm{a}}$ Source: this study. ${ }^{\mathrm{b}}$ Source: Ref. 7.

\section{Development of orchid specific primers for amplification of the rDNA-ITS region}

PCR primers (18d, 5'-CACACCGCCCGTCECTCCT ACCGATTG-3' and 26S, 5' -AGACTCCTTGGTCCG TGTTTCAAGAC- $3^{\prime}$ ) of rDNA sequences were designed based on conserved sequences between rice and several eukaryotes ${ }^{19}$. These primers were used to amplify the region from partial sequence of $18 \mathrm{~S}$ rDNA, ITS1, 5.8S rDNA, ITS2, to partial sequence of 26S rDNA of two orchid samples, one native species (Dendrobium virgineum) and one cultivated variety (Dendrobium cv. Khaosanan). Standard PCR reaction was performed using $1 \times \mathrm{PCR}$ buffer, $2 \mathrm{mM} \mathrm{MgCl}$, $0.2 \mathrm{mM}$ dNTPs, $0.25 \mu \mathrm{M}$ specific primers, $0.5 \mathrm{U}$ of Taq DNA polymerase (Invitrogen), and 25 ng genomic DNA in a final reaction volume of $20 \mu \mathrm{l}$. PCR cycling conditions contained the initial denaturation at $94{ }^{\circ} \mathrm{C}$ for $3 \mathrm{~min}$, followed by 35 cycles of denaturation at $94{ }^{\circ} \mathrm{C}$ for $30 \mathrm{~s}$, primer annealing at $55^{\circ} \mathrm{C}$ for $30 \mathrm{~s}$, primer extension at $72^{\circ} \mathrm{C}$ for $45 \mathrm{~s}$, then postcycling extension at $72^{\circ} \mathrm{C}$ for $10 \mathrm{~min}$. The amplified products were examined by electrophoresis on $1 \%$ agarose gel. The DNA fragments were subsequently extracted from the ethidium bromide-stained gel and ligated with pGEM-T Easy Vector System I (Promega). The ligated products were transformed into Escherichia coli DH5 $\alpha$ competent cells. The nucleotide sequence of the DNA fragments was determined by Macrogen Sequencing Service (Macrogen). The nucleotide sequence was compared against the National Centre for Biotechnology Information (NCBI) database using the programs BLASTX and BLASTN (www.ncbi. nlm.nih.gov/BLAST). All nucleotide sequences were deposited at DDBJ. Novel orchid-specific primers, OrRNA1 and OrRNA2, were subsequently designed based on the conserved sites of two orchids and other plants sequences (Table 1) to amplify the ITS region comprising ITS1, 5.8S rDNA and ITS2 in all Dendrobium species. 


\section{PCR-RFLP analysis}

Nuclear ITS and cpDNA fragments were amplified and subsequently cut with several restriction enzymes to provide PCR-restriction fragment length polymorphism (PCR-RFLP). For nuclear ITS fragments, OrRNA1 and OrRNA2 primers were used to perform the PCR. Simultaneously, cpDNA fragments including trnS to trnfM, psbC to trnS, and trnH to trnK regions were obtained using the primer sets from Ref. 7 (Table 1). Standard PCR reaction was carried out using $1 \times$ PCR buffer, $2 \mathrm{mM} \mathrm{MgCl}_{2}, 0.2 \mathrm{mM}$ dNTPs, $0.25 \mu \mathrm{M}$ specific primers, $0.5 \mathrm{U}$ of Taq DNA polymerase (Invitrogen), and $100 \mathrm{ng}$ genomic DNA in a final reaction volume of $100 \mu \mathrm{l}$. PCR cycling conditions contained the initial denaturation at $94^{\circ} \mathrm{C}$ for $3 \mathrm{~min}$, followed by 35 cycles of denaturation at $94{ }^{\circ} \mathrm{C}$ for $45 \mathrm{~s}$, primer annealing at $55^{\circ} \mathrm{C}$ for $60 \mathrm{~s}$, primer extension at $72{ }^{\circ} \mathrm{C}$ for $60 \mathrm{~s}$, then postcycling extension at $72{ }^{\circ} \mathrm{C}$ for $5 \mathrm{~min}$. The amplicons from each sample were digested with several restriction enzymes following the manufacturer's instruction (New England Biolabs). The digested DNAs were fractionated by electrophoresis on $2 \%$ agarose gel and stained with ethidium bromide. The investigation of the DNA restriction patterns of all Dendrobium species were performed repeatedly at least twice.

\section{Data analysis}

PCR-RFLP bands were manually scored as 1 (for presence) and 0 (for absence) from the images of the gels. Both monomorphic and polymorphic bands were included in the data set to avoid bias estimation of genetic variation. The resulting binary data matrix was calculated using a simple matching coefficient ${ }^{20}$ with FreETree software ${ }^{21}$. The dendrogram was subsequently constructed using the similarity matrix with the unweighted pair-group method with arithmetic averages (UPGMA) with 1000 permutations of bootstrapping using FREETREE, and the tree was displayed using MEGA4 $4^{22}$.

\section{RESULTS AND DISCUSSION}

To develop Dendrobium rDNA specific primers, approximately $1300 \mathrm{bp}$ DNA fragments of rDNA-ITS were amplified from $D$. virgineum and Dendrobium cv. Khaosanan. Partial nucleotide sequences of the 1300 bp fragments (accession no. AB671740, $\mathrm{AB} 671741$ for D. virgineum and $\mathrm{AB} 671742$, AB671743 for Dendrobium cv. Khaosanan) were deposited in the database. The sequences of the two orchids were then aligned with rDNA-ITS region of several plant species, and the new specific primers, (a)

Taql

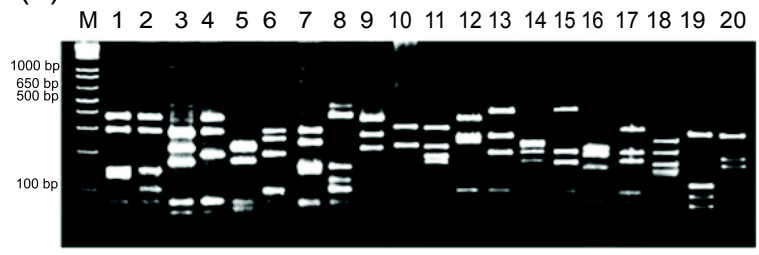

(b)

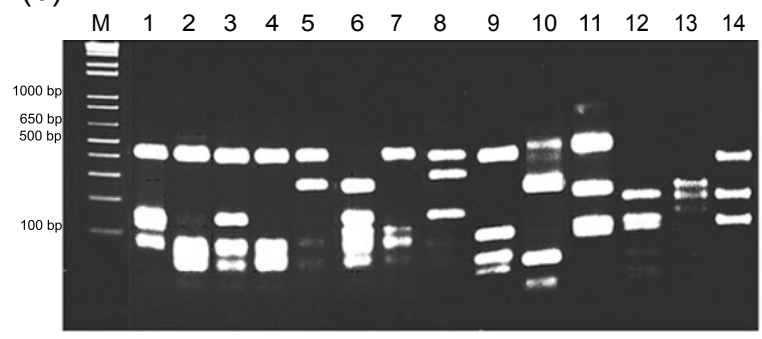$$
\text { (c) }
$$

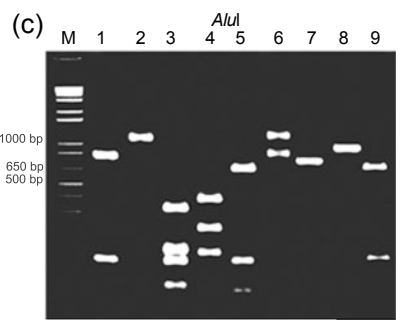

(d) Hhal

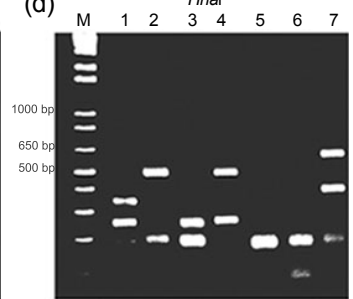

(e)

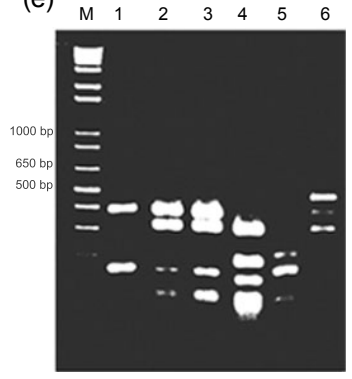

(f)

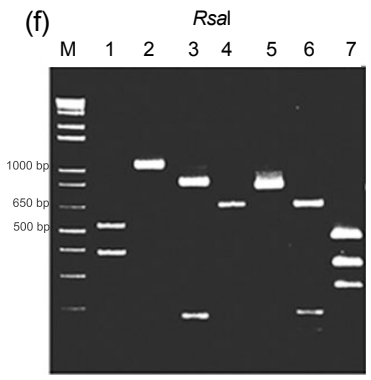

Fig. 1 PCR-RFLP patterns of rDNA-ITS of Dendrobium orchids after digestion with TaqI (a), HaeIII (b), AluI (c), $H h a \mathrm{I}(\mathrm{d}), \operatorname{Hinf\mathrm {I}}(\mathrm{e})$ and $R s a \mathrm{I}$ (f). The number above each lane are the type of DNA patterns found from each primerenzyme combination. $\mathrm{M}$ is a $1 \mathrm{~kb}$ plus DNA ladder.

OrRNA1 - OrRNA2 (Table 1), were developed for ensuring the effective amplification of all Dendrobium species. Approximately $1100 \mathrm{bp}$ of amplicons were observed in all 25 Dendrobium species. Six restriction enzymes having 4 bp or $6 \mathrm{bp}$ with degenerated bases in the recognition sites for higher probability of restriction sites found on the amplicons, were subsequently used to produce the unique restriction pattern for each species. The DNA restriction pattern of $9,14,6,7,7$, and 20 types were generated from the enzymes AluI, HaeIII, HinfI, HhaI, RsaI, and TaqI, respectively, (Fig. 1, and Table 2). When considered 
Table 2 PCR-RFLP patterns of rDNA-ITS and chloroplast DNA of Dendrobium species.

\begin{tabular}{|c|c|c|c|c|c|c|c|c|c|c|c|c|c|}
\hline \multirow[t]{2}{*}{ Dendrobium sp. } & & \multirow[t]{2}{*}{ Section $^{1}$} & \multicolumn{11}{|c|}{ PCR-RFLP patterns of sample generated by each primer-enzyme combination } \\
\hline & & & $A l u \mathrm{I}^{\mathrm{a}}$ & Hae III $^{\mathrm{a}}$ & $\operatorname{Hinf\mathrm {I}^{\mathrm {a}}}$ & $H h a \mathrm{I}^{\mathrm{a}}$ & $R s a \mathrm{I}^{\mathrm{a}}$ & $\operatorname{Taq} \mathrm{I}^{\mathrm{a}}$ & $\operatorname{HinfI}^{\mathrm{b}}$ & $R s a \mathrm{I}^{\mathrm{b}}$ & $\operatorname{Taq} \mathrm{I}^{\mathrm{b}}$ & $\operatorname{HinfI}^{\mathrm{c}}$ & $\operatorname{Hinf\mathrm {I}^{\mathrm {d}}}$ \\
\hline D. hercoglossum & DHER & Bre & 1 & 3 & 1 & 3 & 3 & $4^{*}$ & 1 & 1 & 1 & 2 & 1 \\
\hline D. palpebrae & DPAL & Cal & 2 & 14 & 2 & 3 & 2 & 13 & 4 & 1 & 1 & 1 & 7 \\
\hline D. lindleyi & DLIN & Cal & 2 & $9^{*}$ & 2 & 2 & 3 & $11^{*}$ & 4 & 1 & 1 & 2 & 6 \\
\hline D. signatum & DSIG & Den & 1 & 1 & 1 & 1 & 1 & $1^{*}$ & 1 & 1 & 1 & 2 & 1 \\
\hline D. fridericksianum & DFRI & Den & 1 & 1 & 1 & 1 & 1 & $2^{*}$ & 1 & 1 & 1 & 2 & 1 \\
\hline D. chrysanthum & DCHRY & Den & 1 & $2^{*}$ & 2 & 2 & 2 & 3 & 2 & 1 & 1 & 2 & 2 \\
\hline D. lituiflorum & DLIT & Den & 1 & 4 & 2 & 2 & 4 & $5^{*}$ & 2 & 1 & 1 & 1 & $3^{*}$ \\
\hline D. anosmum & DANO & Den & 5 & 3 & 2 & 5 & 2 & 9 & 2 & 7 & 1 & 1 & 1 \\
\hline D. finlayanum & DFIN & Den & $6^{*}$ & $8^{*}$ & 1 & $7^{*}$ & 3 & $10^{*}$ & 2 & 7 & 1 & 1 & 1 \\
\hline D. albosanguineum & DALB & Den & $9^{*}$ & 3 & 2 & $6^{*}$ & 2 & $12^{*}$ & 2 & 7 & 1 & 1 & 6 \\
\hline D. parishii & DPAR & Den & 5 & 3 & 2 & 5 & 2 & 9 & 4 & $6^{*}$ & $4^{*}$ & 2 & 1 \\
\hline D. primulinum & DPRI & Den & 2 & 4 & 2 & 2 & $6^{*}$ & $14^{*}$ & $6^{*}$ & 1 & 1 & 1 & 1 \\
\hline D. unicum & DUNI & Den & $8^{*}$ & $12^{*}$ & 2 & 2 & 2 & 13 & 1 & 1 & 1 & 2 & 5 \\
\hline D. capillipes & DCAP & Den & 2 & 3 & 2 & 2 & 2 & 3 & 2 & $4^{*}$ & $3^{*}$ & 1 & 4 \\
\hline D. dixanthum & DDIX & Den & 2 & $13^{*}$ & $6^{*}$ & 3 & 2 & $20^{*}$ & 4 & 1 & 2 & 1 & 7 \\
\hline D. ellipsophyllum & DELL & Dis & $4^{*}$ & $7^{*}$ & 2 & 5 & 2 & $8^{*}$ & 2 & 7 & 1 & 1 & 1 \\
\hline D. cruentum & DCRUE & For & 2 & 5 & $3^{*}$ & 3 & 2 & $6^{*}$ & 2 & 7 & 1 & 2 & 5 \\
\hline D. formosum & DFOR & For & 3 & 6 & 2 & 4 & 2 & 7 & 3 & 2 & 2 & 1 & 4 \\
\hline D. infundibulum & DINF & For & 2 & $10^{*}$ & 2 & 3 & 2 & 13 & $5^{*}$ & $5^{*}$ & 1 & 2 & 7 \\
\hline D. virgineum & DVIG & For & $7^{*}$ & $11^{*}$ & $4^{*}$ & 2 & $5^{*}$ & $16^{*}$ & $8^{*}$ & $3^{*}$ & 1 & 2 & 4 \\
\hline D. christyanum & DCHRI & For & 1 & 3 & $5^{*}$ & 3 & 3 & $18^{*}$ & 2 & 1 & 1 & 1 & 2 \\
\hline D. scabrilingue & DSCA & For & 2 & 14 & 2 & 3 & $7^{*}$ & $19^{*}$ & 1 & 7 & 2 & 2 & 6 \\
\hline D. crumenatum & DCRUM & Rho & 3 & 6 & 2 & 4 & 2 & 7 & 3 & 2 & 2 & 1 & 4 \\
\hline D. compactum & DCOM & Sta & 2 & 5 & 2 & 2 & 2 & $15^{*}$ & $7^{*}$ & 1 & 1 & 1 & 1 \\
\hline D. acerosum & DACE & Str & 2 & 3 & 1 & 3 & 4 & $17^{*}$ & $9^{*}$ & 1 & 1 & 2 & 1 \\
\hline
\end{tabular}

${ }^{\mathrm{a}} \mathrm{rDNA},{ }^{\mathrm{b}} \operatorname{trnS}-\operatorname{trnfM},{ }^{\mathrm{c}} \mathrm{psbC}-\operatorname{trnS},{ }^{\mathrm{d}} \operatorname{trnH}-\operatorname{trnK}$

* The number with asterisk represents a unique pattern which can be used to identify the respective species by only one primer enzyme combination.

${ }^{1}$ Bre: Breviflores; Cal: Callista; Den: Dendrobium; Dis: Dictichophyllum; For: Formosae; Rho: Rhopalanthe; Sta: Stachyobium; Str: Strongyle

(a)

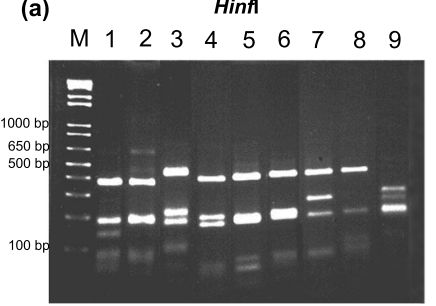

(b) Taql

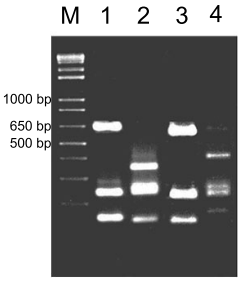

(c)

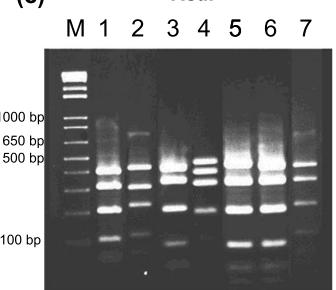

(d) ${ }_{M}$ Hinf

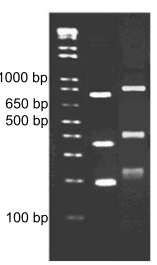

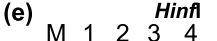

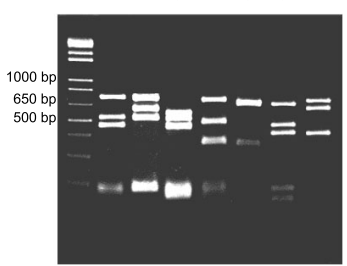

Fig. 2 PCR-RFLP patterns of cpDNA of Dendrobium orchids after digestion with restriction enzyme; (a) trnS-trnfM primer/HinfI, (b) trnS-trnfM primer/TaqI, (c) trnS-trnfM primer/RsaI, (d) psbC-trnS primer/HinfI, and (e) trnH-trnK primer/HinfI. The number above each lane are the type of DNA patterns found from each primer-enzyme combination. $\mathrm{M}$ is a $1 \mathrm{~kb}$ plus DNA ladder.

together, the combined restriction patterns of six enzymes could be classified into 23 classes. Almost all Dendrobium species used in this study showed the unique DNA pattern and could be differentiated from each other, except for the digested DNA patterns of D. crumenatum and D. formosum, as well as D. anosmum and D. parishii, which had the same pattern.

In case of cpDNA, three primer pairs including trnS to trnfM, psbC to trnS, and trnH to trnK regions were obtained ${ }^{7}$ (Table 1). Five effective primerenzyme sets of PCR-RFLP of cpDNA were performed to determine variation of the DNA pattern. Approx- imately $1100 \mathrm{bp}$ of PCR products were found from all 25 Dendrobium species using trnS-trnfM primers. These amplicons were then cut with seven restriction enzymes, in which AluI, HaeIII, HhaI, and MboI produced one type, while HinfI, TaqI, and RsaI produced 9, 4, and 7 PCR-RFLP types, respectively, (Fig. 2a, 2b, 2c, Table 2). Additionally, psbC-trnS primers were used, and about 1500 bp PCR fragments from all species were subsequently digested with HaeIII and HinfI. Two definite polymorphic PCR-RFLP types, however, were found using HinfI (Fig. 2d, Table 2). Finally, amplification with trnH-trnK primers gave about $2100 \mathrm{bp}$ fragments which produced 7 definite 


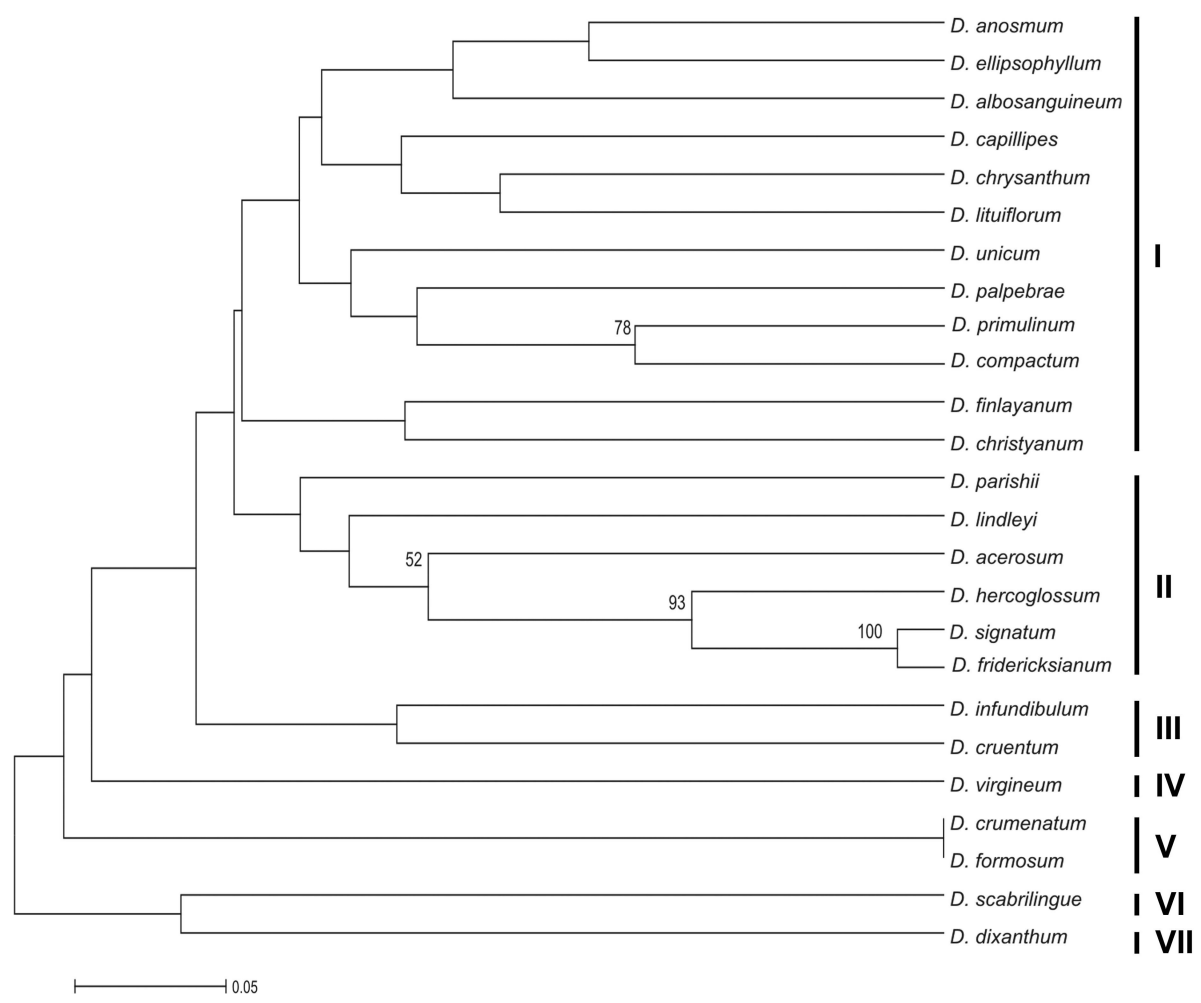

Fig. 3 Dendrogram of 25 Thai native Dendrobium species using UPGMA cluster analysis based on genetic similarities of DNA fingerprint from PCR-RFLP of the rDNA-ITS with six enzymes and five primer-enzyme combinations of cpDNA. Numbers (I-VII) indicates seven clusters in the dendrogram.

polymorphic PCR-RFLP types after digestion with HinfI enzyme (Fig. 2e, Table 2). The PCR-RFLP patterns of the cpDNA with five primer-enzyme sets were further combined into 20 classes. Among these classes, only 17 unique classes of 17 Dendrobium species have been found. The discriminatory power of PCR-RFLP of chloroplast DNA within and among species in the genus Abies has also been reported, in which some species could not be differentiated ${ }^{12}$. Chloroplast DNA indicates common maternal inheritance, suggesting that the cpDNA of some species might have evolved from closely related maternal lineage. These results collectively suggest that analysis of cpDNA is less informative than analysis of nuclear rDNA-ITS in Dendrobium species. The efficacy of PCR-RFLP of rDNA-ITS has also been reported in mushroom $^{23}$ and Withania somnifera ${ }^{10}$. Notably, when the two data sets of rDNA-ITS and cpDNA were combined, 23 Dendrobium spp. could be identified by 24 classes of PCR-RFLP patterns. The DNA patterns of $D$. anosmum and $D$. parishii, which could not be discriminated by PCR-RFLP of rDNA-ITS, could be distinguished, whereas the D. crumenatum and D. formosum still had the same pattern, suggesting that the

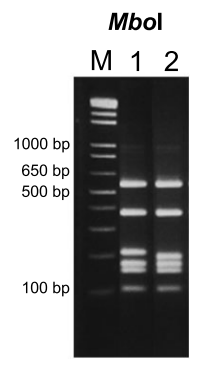

Fig. 4 PCR restriction patterns of D. crumenatum (1) and D. formosum (2) after amplification of cpDNA using psbCtrnS primer and cut with $\mathrm{MboI}$. M is a $1 \mathrm{~kb}$ plus DNA ladder.

DNA regions of $D$. crumenatum and $D$. formosum used in this study are highly similar. These results were seen in the dendrogram where they were in the same clade (Fig. 3). However, if the amplified DNA fragments using psbC-trnS primer of $D$. crumenatum and $D$. formosum were cut by $M b o \mathrm{I}$, they could also be distinguishable (Fig. 4).

Identification of Dendrobium species by molecular techniques has been used in several studies including DNA marker-based and sequence-based ap- 


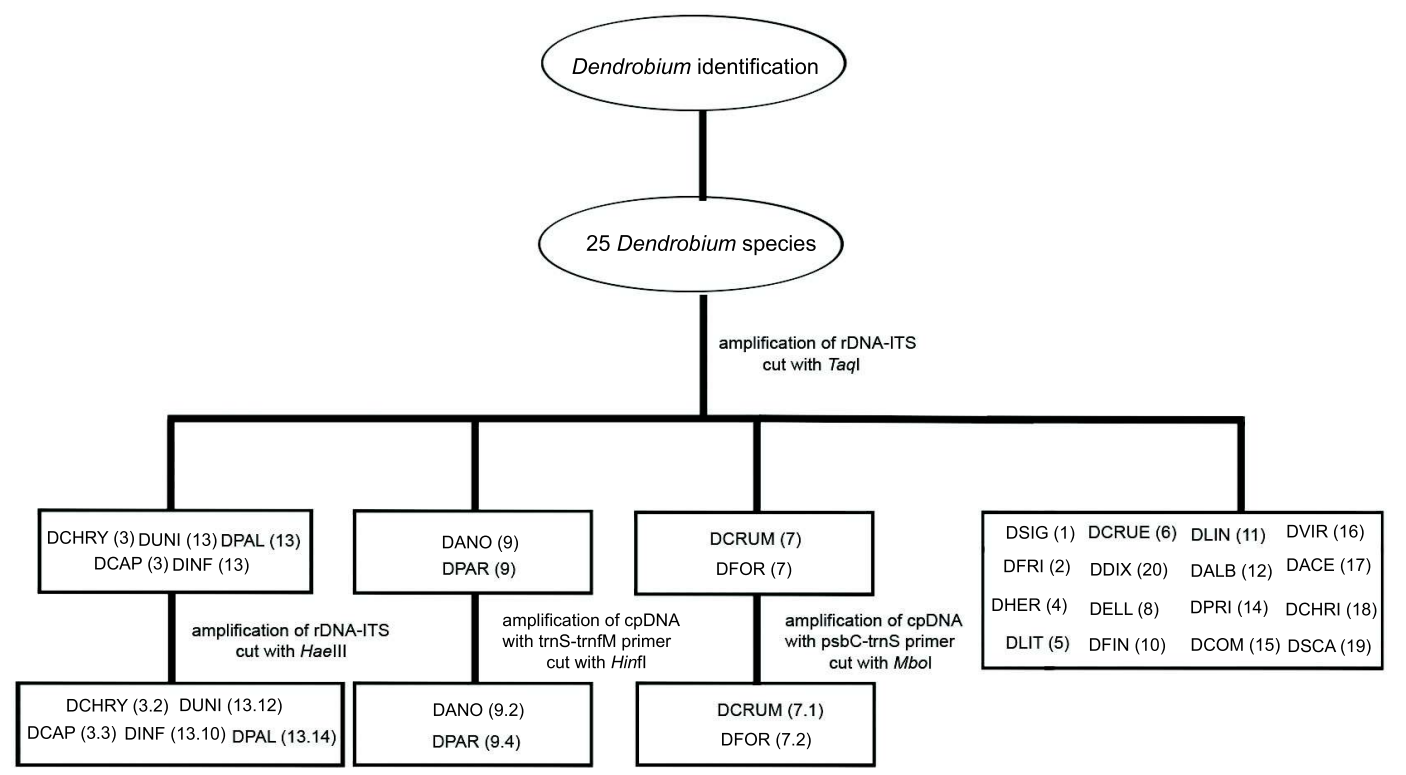

Fig. 5 Schematic representation of the effective procedure for identifying 25 native Dendrobium spp. found in Thailand. Firstly, amplification of rDNA-ITS were performed with the unknown Dendrobium spp., and then cut with TaqI, which can identify 16 Dendrobium spp. with a unique DNA pattern as shown by the number in parentheses (the same as the number with asterisk in Table 2). If the DNA pattern in the first step are type 3 or type 13, then cut the rDNA-ITS with HaeIII which can further identify the other five species. If the DNA pattern of the first step is type 9, the amplification of cpDNA is then conducted with trnS- trnfM primer followed by cutting with HinfI, which can identify two species. However, if the DNA pattern of the first step is type 7, the amplification of cpDNA is conducted with psbC-trnS primer followed by cutting with MboI, which can identify the two species. The species identified using 2 steps are shown by the number with two digits, where the first digit represents the DNA pattern of rDNA-ITS/TaqI and the second one is the DNA pattern of the second primer enzyme combination. The abbreviations of each species are described in Table 2.

proaches. The sequences of rDNA-ITS and the sequences of $m a t K$ and $r b c L$ genes of cpDNA ${ }^{13,15}$ have been used to provide species identification of some Dendrobium plants. The sequence-based procedure could be the basis of a reliable protocol for species identification and could provide taxonomic information for clarifying evolutionary relevance of the taxa studied $^{24,25}$. Nonetheless, this method is costly and time-consuming since it needs PCR amplification and DNA sequencing. The local orchid-research laboratory might not have all necessary equipment and materials. On the other hand, genetic diversity of 31 Dendrobium species from Yunnan region of China has been revealed through ISSR markers ${ }^{17}$. This method can provide species-specific ISSR markers in several species. The multiple bands from each marker exhibited in each species however made it difficult to determine those specific markers. In contrast, PCR-RFLP utilizes the digestion of amplified DNA fragments with a restriction endonuclease to display restriction site polymorphisms ${ }^{9}$. This approach could be performed simply through specific PCR products using a standard agarose gel electrophoresis. Species verification can therefore be done at the local research laboratory. PCR-RFLP approach has been used to investigate the phylogenetic relationship among 13 Dendrobium species using chloroplast $r b c L$ gene ${ }^{16}$.

Even though the genetic relationship of various Dendrobium spp. has been reported ${ }^{14,15}$, the study of the phylogenetic relationship of several Thai native Dendrobium species has never been conducted. In this study, the dendrogram was reconstructed by the binary data matrix of PCR-RFLP from rDNA-ITS and cpDNA data sets (Fig. 3). These relationships were however not consistent with the taxonomic classification (section) and with our phylogenetic analysis based on DNA sequence (Srikulnath et al unpublished data), suggesting that the number of primer/enzyme combinations for PCR-RFLP analysis should be increased for more accurate investigation of the genetic relationship of each native Dendrobium spp.

In the present study, the effective procedure for identification of 25 native Dendrobium spp. in Thailand was clarified (Fig. 5). Firstly, all Dendrobium 
spp. were amplified by PCR at rDNA-ITS region followed by cutting with $\mathrm{Taq}$ I as the first step. Sixteen Dendrobium species could be differentiated with a unique DNA pattern as shown by the number in parentheses (the same as the number with asterisk in Table 2) namely, D. signatum (1), D. fridericksianum (2), D. hercoglossum (4), D. lituiflorum (5), D. cruentum (6), D. ellipsophyllum (8), D. finlayanum (10), D. lindleyi (11), D. albosanguineum (12), D. primulinum (14), D. compactum (15), D. virgineum (16), D. acerosum (17), D. christyanum (18), $D$. scabrilingue (19), and D. dixanthum (20). For the species having the DNA pattern of either type 3 or type 13, the amplified fragments of rDNA-ITS were further cut with HaeIII which could be used to identify the other five species, D. chrysanthum (3.2), D. capillipes (3.3), D. infundibulum (13.10), D. unicum (13.12), and D. palpebrae (13.14). However, if the DNA pattern of the first step was type 9, then cpDNA was amplified with trnS-trnfM primer followed by cutting with HinfI, where $D$. anosmum (9.2) and D. parishii (9.4) were successfully distinguished. Finally, $D$. crumenatum and $D$. formosum which had the same DNA pattern as type 7 from the first step were then differentiated by amplifying the cpDNA with psbC-trnS primer and subsequent cutting with $M b o$ I.

Conclusively, our study provides a rapid, simple and reliable method to identify Dendrobium species, and the DNA patterns of all species in this study could be used as a reference for Dendrobium spp. identification and certification. This study also suggests that PCR-RFLP of rDNA-ITS and cpDNA could be an alternative method for species identification in some plants.

Acknowledgements: This work was financially supported by the National Research Council of Thailand (NRCT). We are very grateful to Amara Thongpan for valuable discussion and to Thiti Kanchanaketu for technical assistance in dendrogram construction. We acknowledge the laboratory of Biotechnology (Plant Tissue Culture section), Chulabhorn Research Institute, Laksi, Bangkok, Thailand, for providing all orchid samples.

\section{REFERENCES}

1. Dressler RL (1993) Phylogeny and Classification of the Orchid Family. Discorides Press, Portland, OR.

2. Leitch IJ, Kahandawala I, Suda J, Hanson L, Ingrouille MJ, Chase MW, Fay MF (2009) Genome size diversity in orchids: consequences and evolution. Ann Bot 104, 469-81.

3. Seidenfaden G (1985) Orchid Genera in Thailand XII.
Dendrobium Sw. Opera Botanica no. 83. Council for Nordic Publications in Botany, Copenhagen.

4. Lavarack B, Harries W, Stocker G (2000) Dendrobium and its Relatives. Timber Press, Portland.

5. Chou CH, Tsai CC (1999) Genetic variation in the intergenic spacer of ribosomal DNA of Imperata cylindrica (L.) Beauv. var. major (Congongrass) population in Taiwan. Bot Bull Acad Sin 40, 319-27.

6. Saar DE, Polans NO (2000) ITS sequence variation in selected taxa of Pisum. Pisum Genet 32, 42-5.

7. Demesure B, Sodzi N, Petit RJ (1995) A set of universal primers for amplification of polymorphic noncoding regions of mitochondrial and chloroplast DNA in plant. Mol Ecol 4, 129-31.

8. Jaramillo-Correa JP, Bousquet J, Beaulieu J, Isabel N, Perron M, Bouillé M (2003) Cross-species amplification of mitochondrial DNA sequence-tagged-site markers in conifer: the nature of polymorphism and variation within and among species in Picea. Theor Appl Genet 106, 1353-174.

9. Konieczny A, Ausubel FM (1993) A procedure for mapping Arabidopsis mutations using co-dominant ecotype-specific PCR-based markers. Plant $J$ 4, 403-10.

10. Mir BA, Koul S, Kumar A, Kaul MK, Soodan AS, Raina SN (2010) Intraspecific variation in the internal transcribed spacer (ITS) regions of rDNA in Withania somnifera (Linn.) Dunal. Indian J Biotechnol 9, 325-8.

11. Ziegenhagen B, Fladung M (1997) Variation in $p s b C$ gene region of gymnosperms and angiosperms as detected by a single restriction site polymorphism. Theor Appl Genet 94, 1065-71.

12. Parducci L, Szmidt AE (1999) PCR-RFLP analysis of cpDNA in the genus Abies. Theor Appl Genet 98, 802-8.

13. Lau DTW, Shaw PC, Wang J, But PPH (2001) Authentication of medicinal Dendrobium species by the internal transcribed spacer of ribosomal DNA. Planta Med 67, 456-60.

14. Tsai CC, Peng CI, Huang SC, Huang PL, Chou CH (2004) Determination of the genetic relationship of Dendrobium species (Orchidaceae) in Taiwan based on the sequence of the internal transcribed spacer of ribosomal DNA. Sci Hort 101, 315-25.

15. Asahina H, Shinozaki J, Masuda K, Morimitsu Y, Satake M (2010) Identification of medicinal Dendrobium species by phylogenetic analyses using matK and $r b c L$ sequences. J Nat Med 64, 133-8.

16. Yukawa T, Ohba H, Cameron KM, Chase MW (1996) Chloroplast DNA phylogeny of subtribe Dendrobiinae (Orchidaceae): insights from a combined analysis based on $r b c L$ sequences and restriction site variation. J Plant Res 109, 169-76.

17. Wang H-Z, Feng S-G, Lu J-J, Shi N-N, Liu J-J (2009) Phylogenetic study and molecular identification of 31 Dendrobium species using inter-simple sequence repeat (ISSR) markers. Sci Hort 122, 440-7. 
18. Dellaporta SL, Wood J, Hicks JB (1983) A plant DNA minipreparation: version II. Plant Mol Biol Rep 1, 19-21.

19. Hillis DM, Dixon MT (1991) Ribosomal DNAmolecular evolution and phylogenetic inference. $Q$ Rev Biol 66, 410-53.

20. Sneath PHA, Sokal RR (1973) Numerical Taxonomy. Freeman, San Francisco.

21. Hampl V, Pavlíček A, Flegr J (2001) Construction and bootstrap analysis of DNA fingerprinting-based phylogenetic trees with the freeware program FreeTree: application to trichomonad parasites. Int J Syst Evol Microbiol 51, 731-5.

22. Kumar S, Tamura K, Nei M (2004) MEGA3: integrated software for molecular evolutionary genetics analysis and sequence alignment. Brief Bioinform 5, 150-63.

23. James TY, Moncalvo J-M, Li S, Vilgalys R (2001) Polymorphism at the ribosomal DNA spacers and its relation to breeding structure of the widespread mushroom Schizophyllum commune. Genetics 157, 149-61.

24. Hebert PD, Cywinska A, Ball SL, deWaard JR (2003) Biological identifications through DNA barcodes. Proc Roy Soc B 270, 313-21.

25. Vogler AP, Monaghan MT (2007) Recent advances in DNA taxonomy. J Zool Systemat Evol Res 45, 1-10. 